\section{BMJ Paediatrics Open}

\title{
Paediatric critical illness associated with respiratory infection: a single-centre, retrospective cohort study
}

\author{
Haifa Alfaraidi, ${ }^{1}$ Kathy Luinstra, ${ }^{2}$ Alireza Eshaghi (D) , ${ }^{3}$ Marek Smieja, ${ }^{4}$ \\ Jonathan B Gubbay, ${ }^{3,5}$ Jeffrey M Pernica (i) ${ }^{1}$
}

To cite: Alfaraidi $\mathrm{H}$, Luinstra K, Eshaghi A, et al. Paediatric critical illness associated with respiratory infection: a singlecentre, retrospective cohort study. BMJ Paediatrics Open 2020;4:e000640. doi:10.1136/ bmjpo-2020-000640

Poster presentation, Association of Medical Microbiology and Infectious Disease Canada Annual Conference, 2018.

Received 13 January 2020 Revised 30 March 2020 Accepted 1 April 2020

Check for updates

(c) Author(s) (or their employer(s)) 2020. Re-use permitted under CC BY-NC. No commercial re-use. See rights and permissions. Published by BMJ.

${ }^{1}$ Department of Pediatrics, McMaster University, Hamilton, Ontario, Canada

${ }^{2}$ Department of Laboratory Medicine, St Joseph's Healthcare Hamilton, Hamilton, Ontario, Canada

${ }^{3}$ Public Health Ontario Laboratory, Public Health Ontario, Toronto, Ontario, Canada

${ }^{4}$ Department of Pathology and Molecular Medicine, McMaste University, Hamilton, Ontario, Canada

Department of Laboratory Medicine and Pathobiology, University of Toronto, Toronto, Ontario, Canada

Correspondence to Dr Jeffrey M Pernica; pernica@ mcmaster.ca

\section{ABSTRACT}

Objectives To describe critically ill children with respiratory infections, classify them by infection syndrome type and determine the prevalence of Mycoplasma pneumoniae detection.

Study design A retrospective, single-centre cohort study. All children aged 2 months-18 years with presumed respiratory infection who were admitted to a tertiary hospital paediatric intensive care unit (PICU) between September 2015 and October 2016 were eligible. Subjects were grouped by clinical syndrome (viral respiratory infection, asthma exacerbation, undifferentiated/ uncomplicated pneumonia, pneumonia complicated by effusion/empyema and 'other'). All subjects had nasopharyngeal swabs tested for respiratory viruses, $M$. pneumoniae and Chlamydia pneumoniae.

Results There were 221 subjects; the median age was 3.1 years; $44 \%$ were female; and $78 \%$ had medical comorbidities. The majority (75\%) was treated with antibiotics, most often ceftriaxone $(90 \%$ of treated children). Those with any pneumonia were significantly less likely to have a respiratory virus identified in their nasopharynges and had significantly higher $C$ reactive protein (CRP) values than those in the viral infection and asthma groups. There were 10 subjects in whom $M$. pneumoniae was detected $(4.5 \%, 95 \% \mathrm{Cl} 2.2 \%$ to $8.2 \%)$. Mycoplasma-positive children were older (difference 3.5 years, $95 \% \mathrm{Cl} 0.66$ to 6.4 years) and had fewer viral coinfections ( $30 \%$ compared with $69 \%, p=0.02$ ). The prevalence of Mycoplasma infection in children aged $>5$ years with any pneumonia was $13.2 \%(95 \% \mathrm{Cl} 4.4 \%$ to $28 \%)$.

Conclusions The majority of participants had respiratory viruses detected and were treated with broad-spectrum antibiotics. Differences in CRP and viral prevalence were observed between children with different infection syndrome types. M. pneumoniae infection was not rare in school-aged children with pneumonia admitted to the PICU. Attention to antibiotic treatment and rapid diagnostic testing for Mycoplasma in older, critically ill children should be considered to optimise management and avert morbidity and mortality from respiratory infection.

\section{BACKGROUND}

Community-acquired pneumonia (CAP) is a leading cause of paediatric hospitalisation in North America. ${ }^{1}$ Children with respiratory
What is known about the subject?

Respiratory viruses and Mycoplasma pneumoniae are commonly detected in children with non-severe pneumonia.

- Guidelines for the management of communityacquired pneumonia (CAP) in children do not advocate first-line empirical treatment with antibiotics active against Mycoplasma nor routine testing for this pathogen.

\section{What this study adds?}

There are clear biochemical (eg, C reactive protein) and microbiological (eg, respiratory virus prevalence) differences between critically ill children with different respiratory infection syndromes.

- Respiratory viruses were detected in $67 \%$ of the entire study cohort, and $M$. pneumoniae was detected in $13.2 \%$ of school-aged critically ill children with severe CAP.

disease severe enough to warrant admission to a paediatric intensive care unit (PICU) represent a minority $(\sim 20 \%)$ of pneumoniarelated hospitalisations, ${ }^{2}$ but infection-related morbidity and mortality are higher in this subgroup. ${ }^{3}$

Streptococcus pneumoniae has long been considered the most important bacterial pathogen causing severe CAP. ${ }^{45}$ Mycoplasma pneumoniae, in contrast, is thought of as a less virulent pathogen, possibly due to the fact that $M$. pneumoniae infection often selfresolves. ${ }^{6}$ Neither the American, Canadian nor British guidelines recommend antimicrobials with activity against $M$. pneumoniae as first-line empiric treatment for paediatric CAP. $^{7-9}$ However, this pathogen is a common cause of CAP, especially in school-aged children; M. pneumoniae was the most commonly identified bacterial pathogen in American children hospitalised with CAP, being detected in $8 \%$ of the overall cohort and in 
$19 \%$ of school-aged children. ${ }^{2}$ A subsequent analysis of these data demonstrated that children with M. pneumoniae infection could not be distinguished reliably on a clinical basis from those without and that, in contrast to dogma, ${ }^{89}$ single lobar infiltrates and pleural effusions were common on chest radiography $(32 \%$ and $26 \%$ of those infected, respectively). ${ }^{10}$ Furthermore, $12 \%$ of those with $M$. pneumoniae infection required intensive care ${ }^{10}$ Clearly, the epidemiology of this common respiratory pathogen-and its effect on the clinical course and prognosis for children with severe CAP-should be evaluated further. The objectives of our study were to describe children admitted to the PICU of McMaster Children's Hospital (MCH) with respiratory infection and to determine the prevalence of $M$. pneumoniae detection in this population.

\section{METHODS}

Setting

$\mathrm{MCH}$ is a tertiary care centre serving a population of approximately 2.3 million residents. At the time of the study, the centre had 159 beds (12 PICU beds) and, on a yearly basis, admitted approximately 6500 children, with over 40000 emergency department visits.

\section{Design}

This was a single-centre, retrospective cohort study. Eligible children were those aged 2 months to 18 years admitted to the MCH PICU from September 2015 to October 2016 with a presumptive respiratory infection, as defined by a discharge diagnosis of any lower respiratory tract infection. Discharge diagnoses for all patients leaving the PICU were reviewed on a biweekly basis by an investigator (HA); we attempted to capture all those with possible respiratory infection to minimise bias. Children aged less than 2 months were not included due to the different epidemiology of respiratory infection in that age group. Furthermore, all eligible subjects had to have had a nasopharyngeal swab (NPS) taken less than a week after admission to the hospital and a respiratory symptom or sign, including at least one of the following: (1) tachypnoea as per age-specific norms (35); (2) cough; (3) increased work of breathing on exam; or (4) auscultatory findings, such as crackles, wheeze or rhonchi. Patients or the public were not involved in study design. No formal sample size calculation was done.

\section{Data collection}

Information was obtained by retrospective chart review using a standardised data collection form. To group study subjects by infection syndrome, the discharge diagnoses of the clinical team were categorised as follows: viral infection without pneumonia (including bronchiolitis and croup), undifferentiated/uncomplicated pneumonia, pneumonia complicated by effusion/empyema, asthma and 'other.' If the clinical team recorded multiple diagnoses from the aforementioned list, they were classified using the following rules:

1. Subjects marked as having both viral infection and pneumonia were classified as having 'pneumonia' if the chest radiograph was read by the radiologist as consistent with pneumonia and as 'viral infection' (without pneumonia) if not.

2. Subjects marked as having both asthma and pneumonia were classified as having pneumonia if the chest radiograph was read by the radiologist as consistent with pneumonia and as 'asthma' if not.

3. Subjects marked as having both viral infection and asthma were classified as having asthma if they were older than 1 year of age and had a history of atopy; if not, they were classified as viral infection.

\section{Laboratory testing}

All children hospitalised with a potentially infectious respiratory illness at MCH have an NPS performed routinely to identify respiratory viruses, as per the institutional Acute Respiratory Infection Surveillance Protocol. NPSs are assayed using a lab-developed multiplex respiratory virus panel ${ }^{11}$ that detects respiratory syncytial virus (RSV) A/B, human metapneumovirus, influenza A/B, parainfluenza I-III, adenovirus and rhinovirus/enterovirus. NPS specimens from eligible subjects were identified and stored. After the surveillance period, NPSs from subjects were batch-tested (ie. test results were not available to treating clinicians) using a Hamilton Regional Laboratory Medicine Programme lab-developed multiplex PCR assay to detect M. pneumoniae and Chlamydia pneumoniae that was validated against sequencing and external quality control materials.

Any MP testing ordered prospectively by treating clinicians in the course of routine care was not processed using the lab-developed PCR assay but at Public Health Ontario Laboratories using a commercial multiplex realtime assay (ProPneumo-1 Assay; Gen-Probe, San Diego, California, USA), which also tests for C. pneumoniae. Samples that tested positive for MP underwent further testing at Public Health Ontario laboratories; nested PCR amplification and DNA sequencing of domain $\mathrm{V}$ of the partial 23S rRNA gene were performed to detect mutations at nucleotide positions 2063 and 2064, which are associated with macrolide resistance. ${ }^{12} 13$

'Confirmed invasive bacterial infections' were defined as those children with a sterile-site culture (ie, blood or pleural fluid) positive for a recognised pathogen. Cultures positive for coagulase-negative staphylococci were categorised as contaminants.

\section{Statistical analysis}

Descriptive statistics to describe subject baseline characteristics were reported as count (per cent) for categorical variables and mean (SD) or median (first quartilethird quartile, labelled as IQR) for continuous variables, depending on the distribution. Normality was assessed visually. t-Tests or linear regression was used to compare 
normally distributed continuous variables. Kruskal-Wallis testing was used when the distribution of the variable differed greatly from the normal distribution. If KruskalWallis testing identified significant differences, nonparametric pairwise multiple comparisons of the groups using Dunn's test with Bonferroni adjustment were done. $\chi^{2}$ or Fisher exact testing was used to compare categorical variables between groups. Alpha was set at 0.05 , with no adjustments for multiple comparisons in this exploratory study. No imputation of missing data was done. Analyses were conducted using STATA V.11.2.

\section{RESULTS}

In the study period, there were 740 children admitted to the PICU; of these, 221 subjects (31\%) had a diagnosis of acute respiratory illness, an NPS taken less than a week after admission, and at least one respiratory tract symptom or sign (table 1 ). The median age was 3.1 years (IQR 1.4-6.0 years) and 44\% were female. The majority of subjects $(78 \%)$ had comorbidities (see table 1$)$. There were 13 subjects $(6 \%)$ who had a tracheostomy, $7(3 \%)$ who were treated with home ventilation, $6(3 \%)$ who were treated with home non-invasive ventilation and 9 (4\%) who were on home oxygen therapy. There were three deaths $(1.3 \%)$ in the cohort and all had comorbidities. Fourteen subjects $(6 \%)$ were not up-to-date with diphtheria-inactivated polio-tetanus-acellular pertussisHaemophilus influenzae b vaccine or 13-valent pneumococcal conjugate vaccine.

In the PICU, the majority of subjects $(n=139,63 \%)$ received high-flow oxygen support; 49 (22\%) received continuous positive airway pressure/bilevel positive airway pressure; 38 (17\%) required conventional mechanical ventilation; and $1(0.45 \%)$ was treated with high-frequency oscillatory ventilation (see table 2). Viral detections were common, with 79 (36\%) subjects positive for rhinovirus/enterovirus, 37 (17\%) positive for RSV and $24(11 \%)$ positive for parainfluenza; only $72(33 \%)$ tested negative for respiratory viruses (see table 3 ). There were seven subjects with confirmed invasive bacterial infections. The median length of stay in the PICU was 3 days (IQR 2-5 days), and the median length of stay in-hospital was 4 days (IQR 3-8 days).

Of the 221 subjects, $50(23 \%)$ were categorised as having had viral infection without pneumonia, 81 (37\%) as uncomplicated pneumonia, $12(5.4 \%)$ as pneumonia complicated by effusion/empyaema, $63(29 \%)$ as an asthma exacerbation and $15(6.8 \%)$ as 'other.' There was considerable overlap in the white blood cell distributions between categories (see table 4 ). C reactive protein (CRP) measurements were clearly different between groups; those with pneumonia (median $45.5 \mathrm{mg} / \mathrm{L}$ ) had significantly higher median CRP values than those in the viral infection (median $12.6 \mathrm{mg} / \mathrm{L}$ ) and asthma (median $7.0 \mathrm{mg} / \mathrm{L}$ ) groups, whereas those with pneumonia complicated by effusion/empyema (median CRP $203.8 \mathrm{mg} / \mathrm{L}$ ) had significantly higher CRP values than
Table 1 Whole-cohort baseline characteristics

\begin{tabular}{|c|c|}
\hline Median age (years) (IQR) & $3.11(1.39-6.02)$ \\
\hline \multicolumn{2}{|l|}{ Age (years), n (\%) } \\
\hline$<1$ & $36(16)$ \\
\hline $1-2$ & $45(20)$ \\
\hline $2-5$ & $63(29)$ \\
\hline $5-10$ & $45(20)$ \\
\hline $10-15$ & $32(14)$ \\
\hline Female, n (\%) & $96(44)$ \\
\hline Fever recorded, $\mathrm{n}(\%)$ & $120(55)$ \\
\hline Median duration of fever (days) (IQR) & $3(2-6)$ \\
\hline \multicolumn{2}{|l|}{ Symptoms, n (\%) } \\
\hline Increased work of breathing & $202(91)$ \\
\hline Cough & $191(87)$ \\
\hline Wheeze & $112(51)$ \\
\hline Stridor & $13(5.9)$ \\
\hline Chest pain & $4(1.8)$ \\
\hline \multicolumn{2}{|l|}{ Antibiotics given before presentation? } \\
\hline Yes, n (\%) & $44(20)$ \\
\hline Amoxicillin & 18 \\
\hline Amoxicillin/clavulanate & 2 \\
\hline Cephalosporins & 10 \\
\hline Macrolides & 10 \\
\hline Other & 11 \\
\hline Comorbid medical conditions & $174(78)$ \\
\hline Asthma & 89 \\
\hline $\begin{array}{l}\text { Other lung disease (including } \\
\text { bronchopulmonary dysplasia) }\end{array}$ & 36 \\
\hline Neurologic/neurodevelopmental & 52 \\
\hline Genetic disease & 26 \\
\hline Cardiac disease & 26 \\
\hline Endocrine disorders & 13 \\
\hline Tracheostomy & 13 \\
\hline Chronic kidney disease & 7 \\
\hline $\begin{array}{l}\text { Immunodeficiency/immunosuppressant } \\
\text { drugs }\end{array}$ & 5 \\
\hline Haemoglobinopathies & 5 \\
\hline Malignancy & 3 \\
\hline Chronic liver disease & 1 \\
\hline Other & 27 \\
\hline Home ventilation/oxygenation, $\mathrm{n}(\%)$ & $16(7)$ \\
\hline Mechanical ventilation & 7 \\
\hline Noninvasive ventilation & 6 \\
\hline Oxygen therapy without ventilation & 3 \\
\hline
\end{tabular}

PICU, paediatric intensive care unit.

all other groups. There were clear differences in the proportions of subjects in each group with respect to viral NPS testing; $90 \%$ of the viral infection group and $72 \%$ of the asthma group had a respiratory virus detected, while only $60 \%$ of the uncomplicated pneumonia group and $25 \%$ of the complicated pneumonia group did $(p<0.0001)$. All of the subjects in the uncomplicated and 


\begin{tabular}{|c|c|}
\hline Median length of stay in PICU (days) (IQR) & $3(2-5)$ \\
\hline \multicolumn{2}{|l|}{ Highest level of respiratory support given in PICU, $n(\%)$} \\
\hline High-frequency oscillatory ventilation, n (\%) & $1(0.45)$ \\
\hline Conventional mechanical ventilation, $\mathrm{n}(\%)$ & $37(17)$ \\
\hline $\begin{array}{l}\text { Continuous positive airway pressure/bilevel positive } \\
\text { airway pressure, } \mathrm{n}(\%)\end{array}$ & $34(15)$ \\
\hline High-flow oxygen by nasal cannula, n (\%) & $96(43)$ \\
\hline Low-flow oxygen $\left(\mathrm{FiO}_{2}>0.4\right)$, n (\%) & $10(4.4)$ \\
\hline Antibiotics given in PICU, $\mathrm{n}(\%)$ & $166(75)$ \\
\hline Ceftriaxone & 149 \\
\hline Azithromycin & 35 \\
\hline Vancomycin & 29 \\
\hline Clindamycin & 25 \\
\hline Ampicillin & 14 \\
\hline Piperacillin-tazobactam & 12 \\
\hline Levofloxacin & 11 \\
\hline Carbapenems & 3 \\
\hline Clarithromycin & 3 \\
\hline
\end{tabular}

PICU, paediatric intensive care unit.

complicated pneumonia groups were treated with antibiotics, compared with $93 \%$ of the other group, $74 \%$ of the viral infection group and $35 \%$ of the asthma group $(p<0.0001)$. The duration of antibacterial treatment was also significantly shorter in the viral infection and asthma groups than in all other groups $(p<0.0001)$, as well as significantly longer in the complicated pneumonia group than in the uncomplicated pneumonia group $(\mathrm{p}=0.02)$.

Of 10 subjects who had specimens tested for M. pneumoniae through testing ordered prospectively by clinicians in the course of routine care, 3 were positive (one sputum,

\begin{tabular}{ll}
\hline \multicolumn{2}{l}{ Table 3 Whole-cohort microbiology } \\
\hline Mucosal testing, $\mathrm{n}(\%)$ & Positive in 156 (71) \\
\hline Rhino/enterovirus, $\mathrm{n}(\%)$ & $79(36)$ \\
\hline RSV, $\mathrm{n}(\%)$ & $24(17)$ \\
\hline Parainfluenza, $\mathrm{n}(\%)$ & $10(5)$ \\
\hline Mycoplasma, $\mathrm{n}(\%)$ & $7(3)$ \\
\hline Metapneumovirus $\mathrm{n}(\%)$ & $6(3)$ \\
\hline Influenza, $\mathrm{n}(\%)$ & $5(2)$ \\
\hline Adenovirus, $\mathrm{n}(\%)$ & \\
\hline Pleural fluid testing & 2 \\
\hline Group A Streptococcus & 1 \\
\hline Streptococcus anginosus & \\
\hline Blood culture testing & 1 \\
\hline Streptococcus pneumoniae & 1 \\
\hline Haemophilus influenzae & 1 \\
\hline Escherichia coli & 1 \\
\hline Enterococcus faecalis &
\end{tabular}

RSV, respiratory syncytial virus. one NPS and one bronchoalveolar lavage). There were an additional seven subjects that were found to have an NPS positive for M. pneumoniae via retrospective study testing. The overall prevalence of $M$. pneumoniae-associated respiratory illness in the study cohort was therefore 10/221 (4.5\%, 95\% CI $2.2 \%$ to $8.2 \%)$. Mycoplasma-positive subjects were significantly older than Mycoplasma-negative children (difference 3.5 years, $95 \%$ CI 0.66 to 6.4 years; $\mathrm{p}=0.02$ ) (table 4). The overall prevalence of Mycoplasma detection in subjects aged $>5$ years with any type of pneumonia was $13.2 \%$ (4 of 33 in the uncomplicated pneumonia group and 1 of 5 in the complicated pneumonia group; $95 \%$ CI $4.4 \%$ to $28 \%$ ). In this older subset, there were zero Mycoplasma-positive subjects in the viral infection or asthma groups.

None of the Mycoplasma-positive group had invasive bacterial infections. Three $(30 \%)$ of the Mycoplasmapositive group had a respiratory viral pathogen detected as compared with $146(69 \%)$ of the Mycoplasmanegative group $(\mathrm{p}=0.02$; see table 5$)$. Antimicrobials were prescribed for significantly longer from the time of admission in the Mycoplasma positives (median 11 days, IQR 7-17 days) as compared with the Mycoplasma negatives (median 5 days, IQR $0-8$ days; $\mathrm{p}=0.02$ ); this difference remained significant when the analysis was restricted to only those subjects with uncomplicated pneumonia (median 12 days as compared with median 7 days, $\mathrm{p}=0.004)$.

Of the 10 Mycoplasma isolates, 5 were macrolidesensitive and 1 harboured the G2063 mutation in the 23S rRNA gene (overall prevalence $17 \%, 95 \%$ CI $0.4 \%$ to $64 \%$ ); 3 isolates were low-level positives and so could not be sequenced. One isolate was not retained. Only half of the subjects with Mycoplasma infection were prescribed macrolide or fluoroquinolone antibacterials.

No study subjects had C. pneumoniae detected in their NPS.

\section{DISCUSSION}

In this retrospective single-centre study, we found that children with acute respiratory illness admitted to the PICU were predominantly preschool-aged, often had medical comorbidities and frequently had viral pathogens detected in their nasopharynges. A minority had $M$. pneumoniae detected in respiratory secretions and even fewer had documented invasive bacterial infections. Despite this, $75 \%$ of the cohort was treated with antibacterials, most commonly ceftriaxone $(90 \%$ of treated children). Children diagnosed with asthma or viral infections were found to differ microbiologically (more viral pathogens detected) and biochemically (lower CRP values) from children diagnosed with pneumonia. Interestingly, $13.2 \%$ (95\% CI $4.4 \%$ to $28 \%$ ) of children diagnosed with pneumonia who were at least 5 years of age were positive for M. pneumoniae. Children who were Mycoplasmapositive were older, had fewer respiratory virus coinfections, were more often treated with antibacterials before 
Table 4 Differences between diagnostic categories

\begin{tabular}{|c|c|c|c|c|c|}
\hline & Viral infection & Asthma & $\begin{array}{l}\text { Pneumonia } \\
\text { (uncomplicated/ } \\
\text { undifferentiated) }\end{array}$ & $\begin{array}{l}\text { Pneumonia } \\
\text { (complicated by } \\
\text { effusion) }\end{array}$ & Other \\
\hline Count (\%) & $50(22)$ & $63(29)$ & $81(37)$ & $12(5.4)$ & $15(6.8)$ \\
\hline Mean WBC (SD) & $12.1(4.3)$ & $13.6(5.0)$ & $13.0(8.1)$ & $19.0(11.0)^{\star}$ & $12.8(7.5)$ \\
\hline missing & 1 & 1 & 1 & 0 & 0 \\
\hline Median CRP (mg/L) (IQR) & $12.6(3.5-28.6)$ & $7.0(3.6-16.4)$ & $45.5(15.2-103) \dagger$ & 203.8 (146.8-274.7)‡ & $23.6(14.6-80.2)$ \\
\hline missing & 28 & 47 & 31 & 4 & 2 \\
\hline No respiratory virus detected & $5(10)$ & $18(29)$ & $32(40)$ & $9(75)$ & $8(53)$ \\
\hline missing & 0 & 0 & 0 & 0 & 0 \\
\hline $\begin{array}{l}\text { Median duration of antibiotics } \\
\text { (days) (IQR) }\end{array}$ & $2(0-4) \S$ & $0(0-1) \S$ & $7(7-10)$ & 23 (14-27)ף & $10(7-14)$ \\
\hline missing & 0 & 0 & 0 & 0 & 0 \\
\hline
\end{tabular}

*Mean of complicated pneumonia group significantly greater than that of the others $(p=0.002)$.

†Median of pneumonia group significantly greater than that of the viral infection group $(p=0.007)$ and the asthma group $(p=0.0009)$ but significantly lower than that of the complicated pneumonia group $(p=0.02)$.

$\ddagger$ Median of complicated pneumonia group significantly greater than those of the viral infection and the asthma group $(p<0.0001)$ and the pneumonia group $(p=0.009)$.

$\S$ Median of the viral infection and asthma groups significantly smaller than those of all other groups $(p<0.0001)$.

IMedian of the complicated pneumonia group also significantly higher than that of the pneumonia group $(p=0.02)$.

CRP, C reactive protein; WBC, white blood cell.

admission and received a longer course of antibacterials in-hospital than Mycoplasma-negative children. Half of the Mycoplasma-positive children did not receive antibacterials active against Mycoplasma.

The fact that respiratory viruses were frequently detected in critically ill paediatric patients with respiratory illness is not surprising, given the epidemiology of respiratory infection in children. Respiratory viruses have long been known to be important causes of paediatric pulmonary disease; for example, it has been estimated that there are at least $50000 \mathrm{RSV}$-associated hospitalisations per year in the USA, with more than a quarter requiring intensive care. ${ }^{14}$ One large recent cohort study enrolling over 2000 children hospitalised for pneumonia (21\% of whom required PICU admission) at three American hospitals detected respiratory viral pathogens in $73 \% .^{2}$ Viral coinfections may be even more common in children with critical illness, given that paediatric patients with bacterial pneumonia with confirmed viral coinfection have been found to have worse outcomes than those without. ${ }^{15}$

It is unfortunate that almost three-quarters of all patients thought to have a purely viral syndrome received treatment

\begin{tabular}{|c|c|c|c|}
\hline & Mycoplasma-positive & Mycoplasma-negative & $P$ value \\
\hline Count & 10 & 211 & $\mathrm{n} / \mathrm{a}$ \\
\hline Age (years) & & & 0.02 \\
\hline Mean (SD) & $8.1(6.1)$ & $4.6(4.4)$ & \\
\hline Median (IQR) & $7.2(2.0-16)$ & $3.0(1.3-6.0)$ & \\
\hline$\%$ greater than 5 years & $60 \%$ & $34 \%$ & \\
\hline With viral infection or asthma diagnosis, $\mathrm{n}(\%)$ & $3(30)$ & $110(51)$ & 0.2 \\
\hline (restricted to subjects $>5$ years) & 0 & $30(42)$ & 0.08 \\
\hline With no detectable respiratory virus in NPS, n (\%) & $7(70)$ & $65(31)$ & 0.02 \\
\hline (restricted to subjects $>5$ years) & $5(83)$ & $33(46)$ & 0.1 \\
\hline Median duration of antibiotic treatment (days) (IQR) & $11(7-17)$ & $5(0-8)$ & 0.02 \\
\hline (restricted to subjects with uncomplicated pneumonia) & $12(10-13)$ & $7(7-10)$ & 0.004 \\
\hline Median length of stay in PICU (days) (IQR) & $4.5(2-8)$ & $3(2-5)$ & 0.1 \\
\hline (restricted to subjects with uncomplicated pneumonia) & $7(2-8)$ & $4(2-7)$ & 0.7 \\
\hline Median length of stay in the hospital (days) (IQR) & $10(5-13)$ & $4(3-8)$ & 0.03 \\
\hline (restricted to subjects with uncomplicated pneumonia) & $13(7-14)$ & $7(3-14)$ & 0.3 \\
\hline
\end{tabular}

NPS, nasopharyngeal swab; PICU, paediatric intensive care unit. 
with antibacterials. Needless to say, neither the Canadian, American nor British guidelines recommend antibiotic treatment for viral lower respiratory tract infections. ${ }^{16-18}$ Furthermore, the vast majority of treated patients received ceftriaxone, which would be appropriate for some children with pneumonia (eg, immunocompromised patients) but not for others (eg, group A streptococcal empyema). It is difficult to make definitive statements about appropriateness, given that we did not examine the precise sequence of antibiotic administration in each patient in relation to the timing of microbiological results. However, the fact that the vast majority of CAP in children is caused by pneumococcus or group A Streptococcus, coupled with the observation that only 14 children $(6 \%)$ received ampicillin, is very suggestive that antimicrobial stewardship was suboptimal in the PICU during the study period.

Our results would argue that routine surveillance for Mycoplasma in school-aged children with pneumonia should be considered, as others have suggested. ${ }^{19}$ Our findings are consistent with other studies that demonstrated that $M$. pneumoniae is found commonly in school-aged children with $\mathrm{CAP}^{2}$ including children admitted to the intensive care unit. ${ }^{10}$ The incidence of $M$. pneumoniae infection does vary widely by location and season, ${ }^{102}$ and so we cannot exclude the possibility that the prevalence observed in our study was higher than those in years before or after. An older iteration of the Canadian Paediatric Society (CPS) guidelines for the management of CAP (circa 2011) recommended routine use of azithromycin for all children with 'severe' pneumonia because of the possibility of 'atypical infection', though diagnostic testing to identify atypical pathogens was not suggested or even mentioned. ${ }^{21}$ One might question whether this practice would represent appropriate antimicrobial stewardship, given that the majority of severe paediatric CAP is likely to be caused by S. pneumoniae. The CPS guidelines were later revised in 2015 and no longer recommend routine treatment with macrolides. ${ }^{8}$ They state that atypical pneumonia should be suspected in children with 'subacute, nonsevere pneumonia, presenting with features such as prominent cough, minimal leukocytosis, and a nonlobar infiltrate' and that azithromycin is recommended 'for suspected or proven Mycoplasma or Chlamydia pneumoniae ${ }^{8}$ Unfortunately, it has been repeatedly demonstrated that these symptoms and signs cannot reliably identify atypical pneumonia ${ }^{1022} 23$, and so it seems likely that many clinicians may not consider the possibility that $M$. pneumoniae may play a significant role in the pathogenesis of critically ill children with respiratory compromise. Based on our data, we would suggest that clinicians be aware that a reasonable proportion of schoolaged children with CAP admitted to the PICU may have an active $M$. pneumoniae infection and would recommend empiric treatment with anti-Mycoplasma agents (eg, macrolides, doxycycline and fluoroquinolones) until diagnostic (molecular) testing results are available. Of course, we cannot be certain of the therapeutic benefit of antibacterials targeting $M$. pneumoniae, one systematic review found no clear difference in outcomes between children treated with Mycoplasma-active agents and those without. ${ }^{24}$ Furthermore, the detection of Mycoplasma in the respiratory tract does not prove causation, as coinfections have been shown to be common ${ }^{10}$ and some investigators have documented high rates of PCR positivity in control persons ${ }^{25}$ (although others have not $\left.{ }^{10} 26\right)$; some investigators have identified novel serological tests that can confirm active infection. ${ }^{27}$ We would agree with other authors who have suggested that specific anti-Mycoplasma treatment might yield significant benefit, especially for those with severe disease, and have called for the execution of a randomised treatment trial. ${ }^{10}{ }^{19}$ However, until results of a definitive treatment trial are available, we feel that the potential benefit of treating critically ill children with Mycoplasma detected in respiratory symptoms outweighs the potential antimicrobial stewardship harms of this strategy.

There were obvious limitations to our study. As noted previously, this was a retrospective design and included only a single centre over a 13-month period; as outbreaks with this pathogen have been frequently described, ${ }^{28}$ we cannot be certain that the prevalence of infection documented in this study is an accurate estimate of children hospitalised with critical respiratory illness in our region of Canada. It is also quite possible that hospital clinicians may not have strictly followed hospital infection control policy and failed to sample the nasopharynges of some patients who otherwise would have been eligible. The study cohort only comprised 221 children and there were only 10 found to be positive for $M$. pneumoniae; consequently, 95\% CIs around our point estimates are wide. Having said that, the prevalence of viral and Mycoplasma detection found in this small study was similar to other estimates. $^{2}$

In conclusion, we found that the majority of children admitted to the PICU with respiratory illness over a 13-month period were positive for respiratory viruses and potentially inappropriate antibiotic treatment was common. M. pneumoniae was detected in $13.2 \%$ of children aged 5 years and older diagnosed with CAP. Effort should be made to distinguish those with plausible bacterial infections from those without, and consideration should be given to empiric anti-Mycoplasma antimicrobial therapy pending the result of rapid molecular diagnostic testing in a subset of critically ill children.

Acknowledgements The authors acknowledge the assistance of Samir Patel, who oversaw the Mycoplasma resistance testing.

Contributors HA designed the study, submitted for funding, did the data collection, aided with analysis and played an important role in manuscript writing JMP conceived the study and played an important role in study design, conduct, analysis and manuscript writing. KL performed microbiological testing and aided with the development of methods. MS and JBG oversaw the microbiological methods and played an important role in study design and manuscript revision. AE performed microbiological testing, aided with the method development and critically revised the manuscript.

Funding This project was supported by a McMaster University Department of Pediatrics Resident Research Grant. JMP was supported by a Hamilton Health Sciences Early Career Award.

Competing interests No, there are no competing interests. 
Patient and public involvement Patients and/or the public were not involved in the design, or conduct, or reporting, or dissemination plans of this research.

Patient consent for publication Not required.

Ethics approval The study was approved by the Hamilton Integrated Research Ethics Board, which waived the requirement for consent in this retrospective study. Provenance and peer review Not commissioned; externally peer reviewed. Data availability statement Data are available upon reasonable request.

Open access This is an open access article distributed in accordance with the Creative Commons Attribution Non Commercial (CC BY-NC 4.0) license, which permits others to distribute, remix, adapt, build upon this work non-commercially, and license their derivative works on different terms, provided the original work is properly cited, appropriate credit is given, any changes made indicated, and the use is non-commercial. See: http://creativecommons.org/licenses/by-nc/4.0/.

ORCID iDs

Alireza Eshaghi http://orcid.org/0000-0001-5150-483X

Jeffrey M Pernica http://orcid.org/0000-0002-4380-5402

\section{REFERENCES}

1 Lee GE, Lorch SA, Sheffler-Collins S, et al. National hospitalization trends for pediatric pneumonia and associated complications. Pediatrics 2010;126:204-13.

2 Jain S, Williams DJ, Arnold SR, et al. Community-acquired pneumonia requiring hospitalization among U.S. children. $N$ Engl $J$ Med 2015;372:835-45.

3 Koh JWJC, Wong JJ-M, Sultana R, et al. Risk factors for mortality in children with pneumonia admitted to the pediatric intensive care unit. Pediatr Pulmonol 2017;52:1076-84

4 Principi N, Esposito S. Emerging problems in the treatment of pediatric community-acquired pneumonia. Expert Rev Respir Med 2018;12:595-603.

5 Ouldali N, Levy C, Minodier P, et al. Long-term association of 13-valent pneumococcal conjugate vaccine implementation with rates of community-acquired pneumonia in children. JAMA Pediatr 2019;173:362-70.

6 Bradley JS, Arguedas A, Blumer JL, et al. Comparative study of levofloxacin in the treatment of children with community-acquired pneumonia. Pediatr Infect Dis J 2007;26:868-78.

7 Harris M, Clark J, Coote N, et al. British Thoracic Society guidelines for the management of community acquired pneumonia in children: update 2011. Thorax 2011;66 Suppl 2:ii1-23.

8 Le Saux Net al, Canadian Paediatric Society, Infectious Diseases and Immunization Committee. Uncomplicated pneumonia in healthy Canadian children and youth: practice points for management. Paediatr Child Health 2015;20:441-5.

9 Bradley JS, Byington CL, Shah SS, et al. The management of community-acquired pneumonia in infants and children older than 3 months of age: clinical practice guidelines by the PIDS and IDSA. Clin Infect Dis 2011;53:e25-76.

10 Kutty PK, Jain S, Taylor TH, et al. Mycoplasma pneumoniae among children hospitalized with community-acquired pneumonia. Clin Infect Dis 2019;68:5-12.

11 Ali M, Han S, Gunst CJ, et al. Throat and nasal swabs for molecular detection of respiratory viruses in acute pharyngitis. Virol $J$ $2015 ; 12: 178$.
12 Matsuoka M, Narita M, Okazaki N, et al. Characterization and molecular analysis of macrolide-resistant Mycoplasma pneumoniae clinical isolates obtained in Japan. Antimicrob Agents Chemother 2004:48:4624-30.

13 Eshaghi A, Memari N, Tang P, et al. Macrolide-Resistant Mycoplasma pneumoniae in humans, Ontario, Canada, 2010-2011. Emerg Infect Dis 2013;19.

14 Arriola CS, Kim L, Langley G, et al. Estimated Burden of CommunityOnset Respiratory Syncytial Virus-Associated Hospitalizations Among Children Aged <2 Years in the United States, 2014-15. J Pediatric Infect Dis Soc 2019. doi:10.1093/jpids/piz087. [Epub ahead of print: 23 Dec 2019].

15 Nolan VG, Arnold SR, Bramley AM, et al. Etiology and impact of coinfections in children hospitalized with community-acquired pneumonia. J Infect Dis 2018;218:179-88.

16 Friedman JN, Rieder MJ, Walton JM, et al. Bronchiolitis: recommendations for diagnosis, monitoring and management of children one to 24 months of age. Paediatr Child Health 2014;19:485-98.

17 Ralston SL, Lieberthal AS, Meissner HC, et al. Clinical practice guideline: the diagnosis, management, and prevention of bronchiolitis. Pediatrics 2014;134:e1474-502.

18 National Institute for Health and Care Excellence. "Bronchiolitis in children: Diagnosis and management". Available: https://www.nice. org.uk/guidance/ng9/resources/bronchiolitis-in-children-diagnosisand-management-pdf-51048523717 [Accessed Last Accessed 2020 March 29].

19 Shah SS. Mycoplasma pneumoniae as a cause of communityacquired pneumonia in children. Clin Infect Dis 2019;68:13-14.

20 Jacobs E, Ehrhardt I, Dumke R. New insights in the outbreak pattern of Mycoplasma pneumoniae. Int J Med Microbiol 2015;305:705-8.

21 Le Saux N, Robinson J. Pneumonia in healthy Canadian children and youth: practice points for management. Paediatr Child Health 2011;16:417-20.

22 Meyer Sauteur PM, Unger WWJ, van Rossum AMC, et al. The art and science of diagnosing Mycoplasma pneumoniae infection. Pediatr Infect Dis J 2018;37:1192-5.

23 Guo W-L, Wang J, Zhu L-Y, et al. Differentiation between Mycoplasma and viral community-acquired pneumonia in children with lobe or multi foci infiltration: a retrospective case study. BMJ Open 2015;5:e006766.

24 Biondi E, McCulloh R, Alverson B, et al. Treatment of Mycoplasma pneumonia: a systematic review. Pediatrics 2014;133:1081-90.

25 Spuesens EBM, Fraaij PLA, Visser EG, et al. Carriage of Mycoplasma pneumoniae in the upper respiratory tract of symptomatic and asymptomatic children: an observational study. PLoS Med 2013;10:e1001444.

26 Nilsson AC, Björkman P, Persson K. Polymerase chain reaction is superior to serology for the diagnosis of acute Mycoplasma pneumoniae infection and reveals a high rate of persistent infection. BMC Microbiol 2008;8:93.

27 Meyer Sauteur PM, Seiler M, Trück J, et al. Diagnosis of Mycoplasma pneumoniae Pneumonia with Measurement of Specific Antibody-Secreting Cells. Am J Respir Crit Care Med 2019;200:1066-9.

28 Waites KB, Talkington DF. Mycoplasma pneumoniae and its role as a human pathogen. Clin Microbiol Rev 2004;17:697-728. table of contents. 